\title{
Evaluation Method and Application of Machine Design Scheme Based on Information Content Measurement Model
}

\author{
Qin Yang ${ }^{*}, 1$ and Yuanyuan $\mathrm{Che}^{2}$ \\ ${ }^{I}$ School of Mechanical Engineering \& Automation, University of Science and Technology Liaoning, Anshan, Liaoning \\ 114051, China \\ ${ }^{2}$ Computering Center of Anshan Normal University Liaoning China, Anshan, Liaoning 114051, China
}

\begin{abstract}
While designing a machine, special design requirements are influenced by various restraint factors in practice. The evaluation of its scheme usually features multi-levels, multi-attributes and a mixed type of both qualitative and quantitative indices. Therefore, this paper focused on the evaluation of the machine design scheme and provided an evaluation method of the machine design scheme based on information content measurement model. This model firstly performed an analysis of all the factors that influence the design application and brought about an evaluation index system on the basis of information independence. Secondly, the model obtained the entire information content of the scheme by establishing information content calculating models of multi-level evaluation indices, and achieved the optimization analysis of machine design scheme on the basis of different amount of information content. Finally, the paper examined the effectiveness of the model with the application example.
\end{abstract}

Keywords: Design scheme, machine, information content, model, multiple attribute decision making.

\section{INTRODUCTION}

Machine design scheme performs optimization and evaluation on the basis of the analysis of functional factors, technical factors, economical factors, social factors, etc. Thus the optimization and evaluation, form a complex systematic decision making process, featuring multi levels, multi-attributes and a mixed type of both qualitative and quantitative indices [1-4]. At present, some scholars have made relevant researches and analysed this complex process with some achievements. Wang Guiping et al. [5] used the fuzzy extension AHP (Analytic Hierarchy Process) method to evaluate the green level of the numerically controlled machine tool and to provide concrete analysis of the project application. Wang Pei et al. [6] delivered researches on the evaluation of the mechanical devices' multi-technical plans on the basis of the combination of fuzzy synthetic evaluation and the grey relevance analysis. Liang Bing et al. [7] analyzed and discussed the systematic decision making problem by adopting the intelligently weighted grey target decision model, and they further brought their analyses into the practice of evaluating prominent dangers of coal and gas. Qu Fuzheng et al. [8] examined the multi-attribute grey fuzzy optimization model of the complex mechanism scheme and the model's application. This paper focused on the information content, as an evaluating factor of the design

*Address correspondence to this author at the School of Mechanical Engineering \& Automation, University of Science and Technology Liaoning, Anshan, Liaoning, 114051, Anshan, China;

Tel/Fax: 15942252210; E-mail: id_yangqin@126.com scheme, to analyze the designed optimization and decision making.

\section{INFORMATION AXIOM}

Axiomatic design was put forward by Prof. Suh, N. P associated with MIT (Massachusetts institute of technology), and is an application of Claude Elwood Shannon's information theory in the field of complex mechanical devices design. It is an effective method used for decision making and systematic analysis, thus providing a design and analysis tool for the measurement and analysis of machine design scheme evaluation. Independent axiom and information axiom are two of the most important concepts in axiomatic design $[9,10]$, and up till now, the optimization of the information axiom complex products design has achieved some results [11-13].

Informational axiom: Based on the measurement model of information contents, the optimum design scheme is the one with the minimum information content on the premise that different evaluation indices are independent in the evaluation index system. The information content $I N_{i}$ is defined by the logarithm of the probability that satisfies the design parameters requirements of the given scheme. It is expressed as:

$$
I N_{i}=-\log _{2} F_{i}=\log _{2}\left(1 / F_{i}\right)
$$

It needs to be illustrated especially at this point that if design parameters of the mechanical devices scheme are continuously observed as random variables, the corresponding probability 
density function $\rho(P)$ usually assumes a stochastic distribution. Subsequently, the satisfying probability $F_{i}$ is expressed as:

$F_{i}=\int_{r_{i 2}}^{r_{i 1}} \rho(P) d P=\rho_{i}$

In the formula, $r_{i 1}$ and $r_{i 2}$ represent the upper limit and lower limit of the satisfying probability, respectively.

In the scheme design application process which is under the influence of multi factors, the satisfying probability $F_{i}$ can be defined by the overlapping area $G_{i}$ of $D_{i}$, the designed range of the scheme, and $S_{i}$, the system range of design scheme. $G_{i}$ is the only area that meets the requirement of the design parameters. Thus, the formula (1) can be expressed in another way as:

$\psi_{i}=-\log _{2} F_{i}=\log _{2}\left(1 / F_{i}\right)=\log _{2}\left(S_{i} / G_{i}\right)$

\section{INFORMATION CONTENT MEASUREMENT MODEL AND ALGORITHM OF MACHINE DESIGN SCHEME}

\subsection{Evaluation System of Machine Design Scheme}

As the evaluation and analysis of machine design scheme form a complex synthetic decision making process with multi-layers and multi-factors, it is necessary to evaluate and analyze it from the perspective of the whole lifecycle. In other words, the evaluation and analysis need to establish corresponding evaluation layers and frames according to different evaluation angles, design elements and factors to complete a synthetic evaluation index system of machine design scheme. The scheme is shown below in Table 1.

Table1. Evaluation index system of machine design scheme.

\begin{tabular}{|c|c|c|}
\hline Target Layer & Criteria Layer & Evaluation Index Layer \\
\hline \multirow{17}{*}{$\begin{array}{l}\text { Evaluation index } \\
\text { system of machine } \\
\text { design scheme }\end{array}$} & \multirow{4}{*}{ technical index } & machining precision \\
\hline & & carrying capacity \\
\hline & & sensitivity \\
\hline & & energy consumption \\
\hline & \multirow{5}{*}{ social index } & pollution \\
\hline & & noise reduction \\
\hline & & useful life \\
\hline & & reliability \\
\hline & & safety \\
\hline & \multirow{4}{*}{ economic index } & processing efficiency \\
\hline & & manufacturability \\
\hline & & compactness \\
\hline & & design cost \\
\hline & \multirow{4}{*}{ maintenance index } & reconfigurability \\
\hline & & testability \\
\hline & & maintainability \\
\hline & & maneuverability \\
\hline
\end{tabular}

\subsection{Information Content Evaluation of Multi-Layer Machine Design Scheme Index}

The evaluation process of machine design scheme has mixed indices of both qualitative indices and quantitative indices. Furthermore, some indices are positive targets while some are reverse targets with the rest featuring fuzzy uncertainty. Based on the different evaluation indices, there are different informational contents' calculating methods. This paper takes the evaluation index system used in the evaluation process of machine design scheme as an example to carry out the calculating methods of informational content under different indices.

\subsubsection{Technical Evaluation Indices Information Content}

Technical evaluation indices signify the accomplishment of the machine's specific properties and serves as measurement indices to determine whether the machine can effectively complete the design function and fulfill the design requirements.

\subsubsection{Machining Precision Information Content}

Machining precision is the key property parameter of the machine. The effectiveness of machine design scheme relies on whether its machine precision fulfills the expected design requirements or the customers' requirements. The information content of machining precision can be determined by the machining precision of both machine design scheme and the design requirement. If the machining precision of machine design scheme is set as $\gamma$ and the design requirement as $\gamma_{0}$, the calculation may adopt the exponential distributed dense function $p$ as $p=e^{-\left|\gamma_{0}-\gamma\right|}$. The calculation of the machine precision information content is:

$$
I N_{\text {mac-acc }}=\log _{2} \frac{1}{p}=\log _{2} e^{\left|\gamma_{0}-\gamma\right|}
$$

\subsubsection{Carrying Capacity Information Content}

Carrying capacity indicates the maximum static load that the machine can bear while working and the properties of that static load. With respect to machine design scheme, carrying capacity is a qualitative descriptive concept because of the diversity of factors generating dynamic load. Therefore, the calculation needs to take advantage of design experience or expert consultation to use a fuzzy membership function $\phi\left(f_{\text {loa-bea }}\right)$ with consecutive numbers within $[0,1]$. The bigger the carrying capacity or the bigger the $\phi\left(f_{\text {loa-bea }}\right)$ the minimum the information content contained in the machine design scheme. The carrying capacity information content is calculated as:

$$
I N_{\text {loa-bea }}=\log _{2} e^{1-\phi\left(f_{\text {loa-bea }}\right)}
$$

\subsubsection{System Sensitivity Information Content}

System sensitivity reflects the quick performance ability of the machine and is a key property parameter of machine's quick design. System sensitivity information content can be 
measured by the processing sensitivity $K_{\text {sen }}$. The higher the $K_{s e n}$, the lesser the information content stored in the machine design scheme. When the sensitivity $K_{\text {sen }}$ is 1 , the design scheme information content should be 0 . Thus the processing sensitivity $K_{\text {sen }}$ information content is expressed as:

$$
I N_{s e n}=\log _{2} e^{1-K_{s e n}}
$$

\subsubsection{Energy Consumption Information Content}

Energy consumption is another key property parameter of the machine design scheme. It will especially play an important role under the circumstances of green processing and resource-efficient processing. The lower energy consumption rate $\rho_{\text {ene-con }}$ implies that the machine design scheme contains the least information content. When the rate is 0 , the information content should be 0 as well. Consequently, the calculation formula of the energy consumption is expressed as:

$$
I N_{\text {ene-con }}=\log _{2} e^{\rho_{\text {ene-con }}}
$$

\subsubsection{Social Evaluation Indices Information Content}

\subsubsection{Pollution Information Content}

Pollution is a social index that refers to the oil pollution, air pollution and solid waste pollution in the surrounding environment caused by the machine design. Pollution is measured by the coefficient $\rho_{p o l-p e r}$, and the smaller the coefficient, the least is the information content stored in the machine design scheme. When pollution is 0 , the information should also be 0 . Thus the formula of pollution is:

$$
I N_{p o l-p e r}=\log _{2} e^{\rho_{\text {pol-per }}}
$$

\subsubsection{Noise Reduction Information Content}

Noise reduction is relevant to the structural arrangementform, the parts' stiffness, the parts' processing and for bringing precision, etc. in the machine design scheme. The value of noise reduction is fuzzy so that the range is defined as consecutive numbers $\phi\left(f_{\text {noi-red }}\right)$ within $[0,1]$ based on the method dealing with fuzzy value. When $\phi\left(f_{\text {noi-red }}\right)$ is 1 , the information content should be 0 . Therefore the formula of noise reduction is:

$$
I N_{\text {noi-red }}=\log _{2} e^{1-\phi\left(f_{\text {noi-red }}\right)}
$$

\subsubsection{Useful Life Information Content}

The useful life information content can be determined by machine design scheme's useful life $C_{\text {ser-lif }}$ and design measurement's useful life $C_{\text {ser-lif }}^{0}$ together. When $C_{\text {ser-lif }}$ approaches $C_{s e r-l i f}^{0}$, the error between the two decreases thus the information content reduces. According to the Student's t-distribution, the calculation of useful life information content can adopt the exponential distribution dense function $p$ as $p=e^{-\left|C_{s e r-l i f}^{0}-C_{\text {ser-lif }}\right|}$. The formula is as follows:

$I N_{\text {mac-acc }}=\log _{2} \frac{1}{p}=\log _{2} e^{\left|C_{\text {ser-lif }}^{0}-C_{\text {ser-lif }}\right|}$

\subsubsection{Processing Reliability Information Content}

Processing reliability can be measured by the reliability $K_{r e l}$. The higher the $K_{r e l}$, the lesser information content the machine design scheme contains. When $K_{r e l}$ is 1 , the information content should be 0 . As a result, the formula of processing reliability information content is expressed as:

$I N_{r e l}=\log _{2} e^{1-K_{r e l}}$

\subsubsection{Processing Safety Information Content}

Processing safety can be measured by the safety $K_{\text {saf }}$. It reflects the scheme's capability of processing operation safety and is also relatively a qualitative concept. Thus, it is also defined by fuzzy language in the way that transforms the fuzzy language into consecutive numbers $K_{\text {saf }}$ within [0, 1]. The calculation formula is:

$$
I N_{s a f}=\log _{2} e^{1-K_{s a f}}
$$

\subsubsection{Economical Evaluation Indices Information Content}

\subsubsection{Processing Efficiency Information Content}

Machine processing efficiency can be measured by specific efficiency value $\eta_{\text {eff-mac }}$. The higher the $\eta_{\text {eff-mac }}$, the less information content the machine design scheme contains. When the efficiency value $\eta_{\text {eff-mac }}$ is 1 , the information content should be 0 . Therefore, the formula of the content in this context is expressed as:

$$
I N_{e f f-m a c}=\log _{2} e^{1-\eta_{e f f-m a c}}
$$

\subsubsection{Manufacturability Information Content}

As the specific form of structural design cannot be determined during the machine scheme designing stage, the calculation can only be based on fuzzy value description of the manufacturability of machine's parts and components. In other words, it is used to limit the value of manufacturability to consecutive numbers $\phi\left(f_{\text {man-fea }}\right)$ within $[0,1]$. When $\phi\left(f_{\text {man-fea }}\right)$ is 1 , the information content should be 0 . Thus the calculation formula is as follows:

$I N_{\text {man-fea }}=\log _{2} e^{1-\phi\left(f_{\text {man-fea }}\right)}$

\subsubsection{Structure Compactness Information Content}

Compactness of the structure reflects the machine's space arranging form and possesses a restraint relationship with the complexity of the design. For achieving structure compactness, a qualitative method is adopted that deals with 
fuzzy value, which uses consecutive numbers $\phi\left(f_{\text {str-com }}\right)$ within $[0,1]$ to describe the degree of structure compactness of the machine. When $\phi\left(f_{\text {str-com }}\right)$ is 1 , the information content should be 0 . Therefore, the formulation of structure compactness information content is expressed as:

$$
I N_{s t r-c o m}=\log _{2} e^{1-\phi\left(f_{s r-c o m}\right)}
$$

\subsubsection{Design Cost Information Content}

Design production cost can be measured by the standardized profit rate of $\operatorname{cost} \lambda_{\cos -\text { pro }}$. The lower the $\lambda_{\cos -p r o}$ , the less information content that the design scheme contains. Thus, the formula is expressed as follows:

$$
I N_{\text {cos- pro }}=\log _{2} e^{\lambda_{\text {cos-pro }}}
$$

\subsubsection{Maintenance Evaluation Indices Information Content}

Reconfigurability, testability, maintainability and maneuverability are all important parameters of the machine's maintenance properties. Consecutive numbers within $[0,1]$ are obtained with the design experience inside the field and with experts' and engineers' consultation. Such numbers represent corresponding evaluation values. If reconfigurability, testability, maintainability and maneuverability are represented by $\kappa_{\text {res-fea }}, \kappa_{\text {tes-fea }}, \kappa_{\text {rep-fea }}$ and $\kappa_{\text {ope-fea }}$ respectively, the four parameters' information content will be $I N_{\text {res-fea }}, I N_{\text {tes-fea }}, I N_{\text {rep-fea }}$ and $I N_{\text {ope-fea }}$. The calculation formulas for them are expressed as:

$$
\begin{aligned}
& I N_{\text {res-fea }}=\log _{2} e^{1-\kappa_{\text {res-fea }}} \\
& I N_{\text {tes-fea }}=\log _{2} e^{1-\kappa_{\text {tes-fea }}} \\
& I N_{\text {rep-fea }}=\log _{2} e^{1-\kappa_{\text {rep-fea }}} \\
& I N_{\text {ope-fea }}=\log _{2} e^{1-\kappa_{\text {ope-fea }}}
\end{aligned}
$$

3.3. Machine Design Scheme Evaluation and the Information Content Measurement Model and Algorithm Implementation

According to the evaluation index system of machine design scheme, information content of the machine design scheme can be described by information matrix as:

$\mathbf{I} N=\left(I N_{T E C}, I N_{S O C}, I N_{E C O}, I N_{M A I}\right)$

In such matrix, $I N_{T E C}, I N_{S O C}, I N_{E C O}$ and $I N_{M A I}$ represent the technical evaluation principle information content, social evaluation principle information content, economical evaluation principle information content and maintenance evaluation principle content, respectively.

If the four information contents (technical, social, economic and maintenance) are weighted as $w_{T E C}, w_{S O C}$,
$w_{E C O}$ and $w_{M A I}$, the total amount of information content of the machine design scheme can be expressed as:

$I N=w_{T E C} \otimes I N_{T E C}+w_{S O C} \otimes I N_{S O C}$

$+w_{E C O} \otimes I N_{E C O}+w_{M A I} \otimes I N_{M A I}$

In the expression, the values of evaluation indices under different principles have the following relations:

$\int I N_{\text {TEC }}=w_{\text {mac-acc }} * I N_{\text {mac-acc }}+w_{\text {loa-bea }} * I N_{\text {loa-bea }}+w_{\text {sen }} * I N_{\text {sen }}+w_{\text {ene-con }} * I N_{\text {ene-con }}$

$I N_{\text {soC }}=w_{\text {pol-per }} * I N_{\text {pol-per }}+w_{\text {noi-red }} * I N_{\text {noi-red }}+w_{\text {mac-acc }} * I N_{\text {mac-acc }}+w_{\text {rel }} * I N_{\text {rel }}+w_{\text {saf }} * I N_{\text {saf }}$

$\left\{I N_{E C O}=w_{e f f-m a c} * I N_{e f f-m a c}+w_{\text {man-fea }} * I N_{\text {man-fea }}+w_{s t r-c o m} * I N_{s t r-c o m}+w_{I N_{\text {cos }-p r o}} * I N_{I N_{\text {cos }- \text { pro }}}\right.$

$I N_{\text {MAI }}=w_{\text {res-fea }} * I N_{\text {res-fea }}+w_{\text {tes-fea }} * I N_{\text {tes-fea }}+w_{\text {rep-fea }} * I N_{\text {rep-fea }}+w_{\text {ope-fea }} * I N_{\text {ope-fea }}$

If there are $n$ machine design schemes, the total amount of all the performance system information content can be expressed as:

$[\mathbf{I} N]_{\Sigma}=[W] \otimes\left[I N_{\Sigma}\right]=\left[w_{T E C}, w_{S O C}, w_{E C O}, w_{M A I}\right] \otimes\left[\begin{array}{cccc}I N_{T E C 1} & I N_{\text {TEC2 }} & \cdots & I N_{T E C n} \\ I N_{S O C 1} & I N_{S O C 2} & \cdots & I N_{S O C n} \\ I N_{E C O 1} & I N_{E C O 2} & \cdots & I N_{E C O n} \\ I N_{M A I 1} & I N_{M A I 2} & \cdots & I N_{M A l n}\end{array}\right]$

$=\left[I N_{\Sigma 1}, I N_{\Sigma 2}, \cdots, I N_{\Sigma n}\right]$

Therefore, the decision making of machine design will choose the one with minimum information content.

\section{APPLICATION EXAMPLE}

This paper takes the machine scheme design of the largesize steel plate processing as an example to test the theory discussed above. The vertical, horizontal and one-side horizontal processing design scheme was attained based on the axiom design and analysis. With the design experience achieved by the field and expert consultation, the corresponding evaluation indices' weight and design parameters value in the Table 2 were obtained on the basis of the evaluation indices mentioned above in the paper.

According to the calculation model and algorithm of the information content of evaluation indices, the corresponding content was obtained as shown in Table $\mathbf{3}$.

Consequently, a synthetic information content sequence was made based on the evaluation index system of machine design scheme which was $\mathbf{I} N=\left(I N_{\Sigma 1}, I N_{\Sigma 2}, I N_{\Sigma 3}\right)=(0.139,0.122,0.128)$. As can be seen from the sequence, the design scheme 2 contains the minimum information content therefore, it is relatively an ideal design scheme.

\section{CONCLUSION}

This paper provides an advanced multiindices information content measurement model of machine design scheme on the basis of the complexity of the scheme and the multi properties of the evaluation system. That model firstly made an analysis of the multi- evaluation factors in the application of the design scheme and obtained the restraint factors such as technical principles, economical principles, social principles and maintenance principles. Furthermore, on the basis of the information axiom, the paper established corresponding information content calculation formulas 
Table 2. Evaluation index system and design parameters.

\begin{tabular}{|c|c|c|c|c|c|c|}
\hline \multirow{2}{*}{ Principles } & \multirow{2}{*}{ Weight } & \multirow{2}{*}{ Evaluation Indices } & \multirow{2}{*}{ Weight } & \multicolumn{3}{|c|}{ Parameter Value } \\
\hline & & & & Vertical & Horizontal & One-Side Horizontal \\
\hline \multirow{4}{*}{ technical } & \multirow{4}{*}{0.40} & machining precision & 0.35 & 0.90 & 0.93 & 0.95 \\
\hline & & carrying capacity & 0.25 & 0.85 & 0.90 & 0.90 \\
\hline & & Sensitivity & 0.20 & 0.92 & 0.90 & 0.92 \\
\hline & & energy consumption & 0.20 & 0.90 & 0.95 & 0.90 \\
\hline \multirow{5}{*}{ social } & \multirow{5}{*}{0.20} & pollution & 0.20 & 0.07 & 0.05 & 0.08 \\
\hline & & noise reduction & 0.20 & 0.90 & 0.85 & 0.93 \\
\hline & & useful life & 0.20 & 0.93 & 0.90 & 0.85 \\
\hline & & reliability & 0.20 & 0.95 & 0.93 & 0.90 \\
\hline & & safety & 0.20 & 0.93 & 0.95 & 0.93 \\
\hline \multirow{4}{*}{ economical } & \multirow{4}{*}{0.20} & processing efficiency & 0.30 & 0.90 & 0.93 & 0.85 \\
\hline & & manufacturability & 0.20 & 0.92 & 0.85 & 0.90 \\
\hline & & compactness & 0.20 & 0.93 & 0.90 & 0.95 \\
\hline & & design cost & 0.30 & 0.05 & 0.07 & 0.05 \\
\hline \multirow{4}{*}{ maintenance } & \multirow{4}{*}{0.20} & reconfigurability & 0.25 & 0.92 & 0.95 & 0.90 \\
\hline & & testability & 0.25 & 0.85 & 0.85 & 0.95 \\
\hline & & maintainability & 0.25 & 0.90 & 0.92 & 0.90 \\
\hline & & maneuverability & 0.25 & 0.85 & 0.92 & 0.85 \\
\hline
\end{tabular}

Table 3. Evaluation indices information content under different design principles.

\begin{tabular}{|c|c|c|c|c|c|c|}
\hline $\begin{array}{l}\text { Evaluation } \\
\text { Indices }\end{array}$ & \multicolumn{2}{|c|}{ Vertical } & $\begin{array}{c}\text { Horizontal } \\
\begin{array}{c}\text { Indices } \\
\text { Information } \\
\text { Content }\end{array}\end{array}$ & \multicolumn{3}{|c|}{ One-Side Horizontal } \\
\hline machining precision & 0.144 & \multirow{3}{*}{0.156} & 0.101 & \multirow{3}{*}{0.115} & 0.072 & \multirow{3}{*}{0.113} \\
\hline carrying capacity & 0.216 & & 0.144 & & 0.144 & \\
\hline energy consumption & 0.144 & & 0.072 & & 0.144 & \\
\hline pollution & 0.101 & \multirow[b]{3}{*}{0.104} & 0.072 & \multirow[b]{3}{*}{0.121} & 0.115 & \multirow[b]{3}{*}{0.135} \\
\hline noise reduction & 0.144 & & 0.216 & & 0.101 & \\
\hline useful life & 0.101 & & 0.144 & & 0.216 & \\
\hline manufacturability & 0.115 & \multirow{3}{*}{0.108} & 0.216 & \multirow{3}{*}{0.133} & 0.144 & \multirow{3}{*}{0.130} \\
\hline compactness & 0.101 & & 0.144 & & 0.072 & \\
\hline design cost & 0.072 & & 0.101 & & 0.072 & \\
\hline reconfigurability & 0.115 & \multirow{4}{*}{0.173} & 0.072 & \multirow{4}{*}{0.130} & 0.144 & \multirow{4}{*}{0.144} \\
\hline testability & 0.216 & & 0.216 & & 0.072 & \\
\hline maintainability & 0.144 & & 0.115 & & 0.144 & \\
\hline maneuverability & 0.216 & & 0.115 & & 0.216 & \\
\hline
\end{tabular}


towards different evaluation indices. Considering the weight of different indices and restraint principles, the paper further established synthetic information content calculation model of the design scheme and made the best design scheme for performance.

\section{CONFLICT OF INTEREST}

The authors confirm that this article content has no conflict of interest.

\section{ACKNOWLEDGEMENTS}

Declared none.

\section{REFERENCES}

[1] H. Caishui, and L. Huabin, "Application of decision model of fuzzy multi-attribute to some program optimization of a certain hydropower project", Engineering Journal of Wuhan University, vol. 38 , no. 5 , pp. $25-27,2005$.

[2] L. Zhifeng, W. Shuwang, and W. Juyong, "green product assessment method based on fuzzy-matter element", China Mechanical Engineering, vol. 18, no. 2, pp. 166-170, 2007.

[3] J. J. Zhang, D. S. Wu, and D. L. Olson, "The method of grey related analysis to multiple attribute decision making problems with interval numbers", Mathematical and Computer Modelling, vol. 42, pp. 991-998, 2005.

[4] G. Zhaohui, Z. Xiaochun, and W. Yao, "Fuzzy comprehensive evaluation method of highway road traffic running state", Journal of China University of Mining and Technology, vol. 43, no. 2, 339344,2014

[5] W. Guiping, J. Yazhou, and Z. Guangwen, "Evaluation method and application of cnc machine tool's green degree based on fuzzyEAHP”, Journal of Mechanical Engineering, vol. 46, no. 3, pp. 141-147, 2010.

[6] W. Pei, Z. Dinghua, and C. Bing, "Evaluation of multi-process plans based on fuzzy comprehensive evaluation and grey relational analysis", Journal of Aerospace Power, vol. 27, no. 9, pp. 20752085, 2012.

[7] L. Bing, Q. Bing, and S. Weiji, "The application of intelligent weighting grey target decision model in the assessment of coal-gas outburst”, Journal of China Coal Society, vol. 38, no. 9, pp. 1611$1615,2013$.

[8] Q. Fuzheng, F. Ye, and W. Xin, "Multi-attribute grey fuzzy optimal selection model of complex mechanism design scheme and its application", Journal of Dalian University of Technology, vol. 45, no. 2, pp. 201-205, 2005.

[9] M. Ogot, "Conceptual design using axiomatic design in a TRIZ framework", Procedia Engineering, vol. 9, pp. 736-44, 2011.

[10] N. P. Suh, and S. -H. Do, "Axiomatic design of software systems", CIRP Annals - Manufacturing Technology, vol. 49, no. 1, pp. 95100,2000

[11] O. Kulak, M. B. Durmuşoğlu, and C. Kahraman, "Fuzzy multiattribute equipment selection based on information axiom", Journal of Materials Processing Technology, vol. 169, no. 3, pp. 337-345, 2005.

[12] W. Tichun, C. Bingfa, and B. Liangfeng, "Multi-attribute optimal selection model of large-scale hydraulic turbine scheme design based on information axiom", Journal of Nanjing University of Aeronautics and Astronautics, vol. 43, no. 6, pp. 822-826, 2011.

[13] K. D. Lee, N. P. Suh, and J. - H. Oh, "Axiomatic design of machine control system", CIRP Annals - Manufacturing Technology, vol. 50, no. 1, pp. 109-114, 2001. 